\title{
Formar, cozer, tirar a cal: testemunhos do fazer cal em Portugal
}

\author{
Forming, cooking, taking lime: testimonies on making \\ lime mortar in Portugal
}

\begin{abstract}
Marluci Menezes
\section{Resumo}

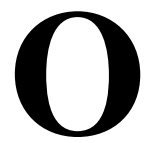

objetivo deste artigo é apresentar e discutir os contextos de algumas "falas" de quem faz a cal, destacando a importância destas "falas" como património intangível. Para efeito, recorre-se a estudos realizados com mestres caleiros no âmbito de projetos de investigação desenvolvidos em Beja (Alentejo/Portugal); explorando ainda alguma da literatura produzida nesta área temática, todavia, privilegiando-se aquela assente em estudos empíricos realizados em Portugal, nomeadamente onde a "voz" do artesão da cal tenha sido expressiva para a compreensão dos processos técnicos tradicionais. Considera-se que o testemunho oral dos artífices da cal pode ser um importante contributo para o ampliar do conhecimento técnico-científico acerca dos processos de produção deste material.

Palavras-chave: Saber técnico-tradicional. Cal. Artesãos. Fonte oral. Património immaterial.

${ }^{1}$ Marluci Menezes 'Laboratorio Nacional de Engenharia Lisboa - Portugal

Recebido em 15/12/17 Aceito em 01/06/18

Abstract

The objective of this paper is to present and discuss the contexts of "speeches" of those who make traditional lime, highlighting the importance of those "speeches" as intangible heritage. For this purpose, studies were carried out with lime craftsmen in the scope of research projects developed in Beja (Alentejo / Portugal). Those studies explore some of the literature produced on this theme, privileging, however, the literature based on empirical studies carried out in Portugal, especially where the "voice" of the artisan of lime was significant for the understanding of traditional technical processes. This article considers that the oral testimony of the lime craftsmen can make an important contribution to expand the technical-scientific knowledge about the processes of production of this material.

Keywords: Traditional knowledge. Lime. Craftsmen. Oral source. Intangible heritage.
\end{abstract}




\section{Introdução}

De entre os obstáculos que se colocam à conservação do património arquitetónico com base em cal, observa-se a dificuldade de reprodução e registo de determinados elementos construtivos. Observa-se ainda o desconhecimento da composição de materiais e de certas técnicas de aplicação e produção (ver Quadro 1). Não menos importante é constatar que a reprodutibilidade e conservação destes processos técnicos tradicionais se encontram ameaçados por uma variedade de questões socioculturais, destacando-se as seguintes: a dificuldade de transmissão cultural do conhecimento técnico, mais normalmente assente num processo de transmissão oral e de aquisição de experiência prática.

Verifica-se ainda a perda de conhecimento tecnológico tradicional em decorrência do desaparecimento ou da inatividade de artesãos mais experientes (porque idosos e reformados). Uma perda que se dá também devido a substituição de processos técnicos e materiais tradicionais por mais modernos.

Quer seja pelo património imaterial que o sabertécnico associado à cal revela, quer seja no âmbito da promoção de processos de conservação mais apropriados para a devida manutenção do património material e arquitetónico, o cenário antes apresentado evidencia a importância de melhor conhecer as tecnologias associadas à cal. Isto é, faz-se fundamental registar as técnicas, os processos de produção, os materiais e as ferramentas tradicionais envolvidas no processo de fazer e aplicar a cal na arquitetura. $\mathrm{O}$ testemunho oral dos artífices da cal pode contribuir para ampliar o conhecimento técnico-científico acerca dos processos tecnológicos relacionados com a produção e a aplicação da cal na construção. Esse testemunho assenta num conhecimento técnicotradicional específico. Mas também reflete uma fala personalizada que, influenciada por formas culturais locais, pelo ambiente e pelas pessoas ao redor, não só revela uma experiência de vida. Introduzindo ainda o que de novo se vai manifestando ao longo dessa experiência técnica.

$\mathrm{O}$ interesse em proceder ao levantamento e registo de informação relacionada com o saber técnicotradicional, no qual resulta como essencial a recolha de testemunho oral, coloca-nos perante a possibilidade de recuperar uma experiência vivida e guardada na memória. Isto porque, através da narrativa a experiência vivida é recuperada e transformada, de certo modo, em presente. Transformando ainda a arte do fazer numa possibilidade de aprendizagem por parte de quem escuta (BOSI, 1979; BENJAMIN, 1986). Pelo que, o recurso à fonte oral/narrativa é central na recolha de informação relacionada com o saber-fazer tradicional, constituindo-se como um "métodofonte-técnica" que nos habilita "criar fontes" (ALBERTI, 2004). Ao que se considera que esta perspectiva contribui para perpetuar determinados saberes e técnicas, a par de que o resgate deste saber pode deter para o campo conservação e restauro do património material.

Ao longo dos últimos anos a temática do saber técnico-tradicional tem sido relevante no enquadramento de projetos de investigação em que o LNEC tem estado envolvido (ver Figura 1). Entre os vários objetivos que constam destes projetos, destaca-se o aprofundar do conhecimento das técnicas, materiais e ferramentas ligadas aos revestimentos de cal existentes em Portugal. Da parte da equipa do LNEC, o levantamento do saber técnico-tradicional tem sobretudo sido efetuado junto de artesãos locais da região do Alentejo, nomeadamente no Distrito de Beja. O refereido levantamento tem-se verificado a partir de entrevistas e visitas de estudos a locais com rico património em cal. Os testemunhos recolhidos através de entrevistas orais têm sido registados em cadernos de notas e gravados, e seguidamente transcritos, sistematizados e analisados. O que melhor habita-nos a conhecer processos de produção, técnicas, quantidades, materiais e ferramentas utilizadas na preparação e aplicação das argamassas e acabamentos.

Portanto, no âmbito do Projeto DB-Heritage Base de dados de materiais de construção com interesse histórico e patrimonial (FCT \& LNEC) -, onde se enquadra este artigo, presentemente procede-se a um levantamento sistematizado de informação. O objetivo é proceder ao registo na referida base de dados - acerca do saber técnicotradicional relacionado com os materiais de construção históricos em contextos de influência portuguesa. Este procedimento tem sido realizado com recurso a informação diretamente recolhida pela equipa do projeto, bem como com recurso a uma pesquisa em fontes secundárias (aqui identificadas com trabalhos de distintos autores). 
Quadro 1 - Desafios à conservação do património com base em cal

\begin{tabular}{|c|c|c|}
\hline Obstáculos à conservação & Aspectos favoráveis à conservação & $\begin{array}{c}\text { Contributos para } \\
\text { promoção da conservação }\end{array}$ \\
\hline 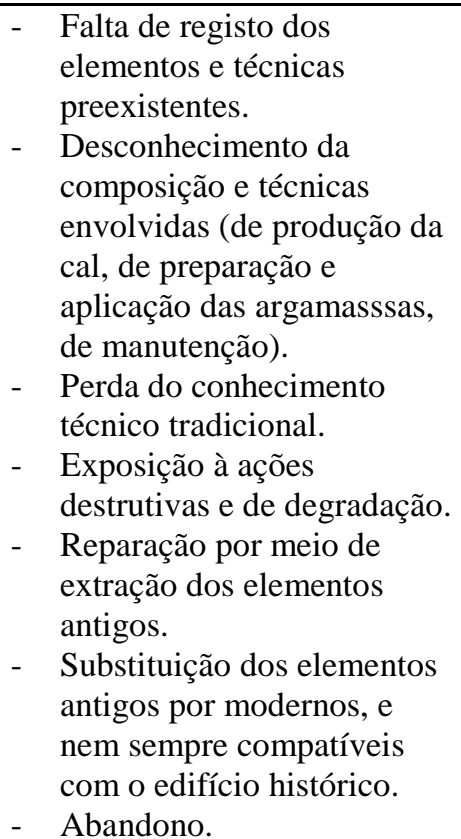 & $\begin{array}{l}\text { - Técnicas distintas e elaboradas. } \\
\text { - Ação protetora das paredes dos } \\
\text { edifícios com maior desempenho } \\
\text { que os materiais modernos. } \\
\text { - Registo de culturas arquitetónicas e } \\
\text { construtivas (património material e } \\
\text { imaterial). } \\
\text { - Influência a imagem e a paisagem } \\
\text { (urbana e rural). } \\
\text { - Com maior desempenho que os } \\
\text { materiais modernos. } \\
\text { - Poder ser compatível com } \\
\text { determinados edifícios históricos. } \\
\text { - Potencial ecológico, económico e } \\
\text { sustentável de salvaguarda e } \\
\text { desenvolvimento. }\end{array}$ & $\begin{array}{l}\text { - Levantamento e registo: } \\
\text { das técnicas antigas e } \\
\text { tradicionais; dos modos de } \\
\text { produção e aplicação; dos } \\
\text { materiais e instrumentos } \\
\text { empregues. } \\
\text { - Restauro orientado pela } \\
\text { máxima conservação e } \\
\text { mínima intervenção, } \\
\text { utilizando materiais } \\
\text { compatíveis com a } \\
\text { estrutura antiga, e sempre } \\
\text { que possível, através da } \\
\text { utilização de materiais } \\
\text { tradicionais. }\end{array}$ \\
\hline
\end{tabular}

Fonte: Menezes, Tavares e Veiga (2012).

Figura 1 -Enquadramento dos projetos em que se tem procedido ao levantamento do saber técnicotradicional

\section{PRESERVe $(2014 \ldots)$}

Preservação de revestimentos do património construído com valor cultural: identificação de riscos, contributo do saber tradicional e novos materiais para conservação e proteção | LNEC
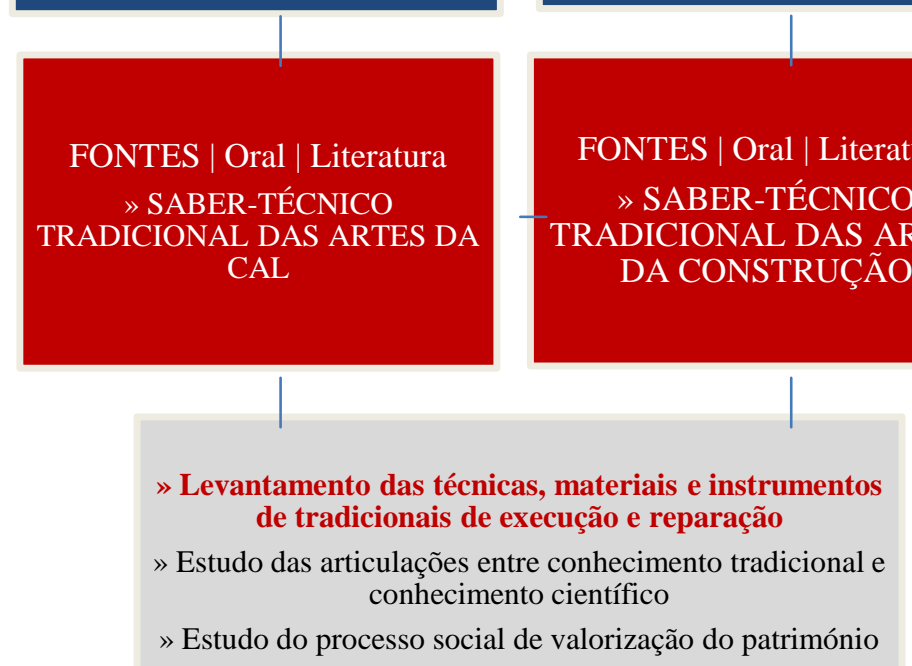
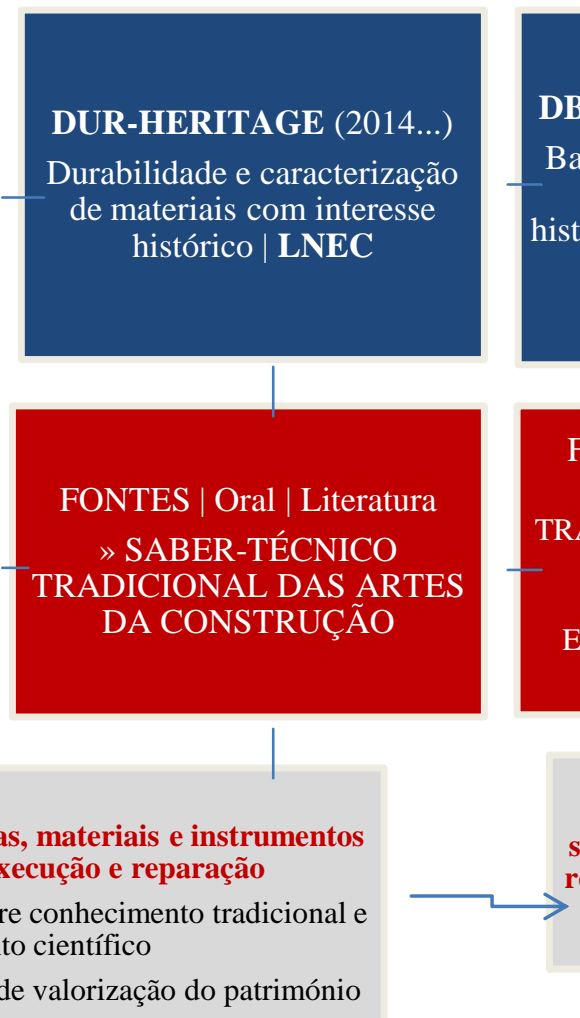

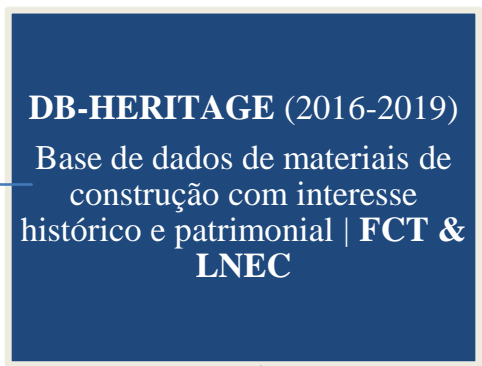

FONTES | Oral | Literatura

» SABER-TÉCNICO

TRADICIONAL DAS ARTES DA CAL

» UTILIZADORES DE

ESTRUTURAS E EDIFÍCIOS HISTÓRICOS

Criação dos fundamentos para a organização e sistematização da informação recolhida numa base de dados de materiais construtivos históricos 
Aqui não são elencados os trabalhos desenvolvidos sobre as estruturas e processos tradicionais de produção de cal. Nem tão pouco visa-se apresentar todos os aspectos do processo tradicional de produção de cal. Os objetivos deste artigo são, por um lado, contribuir para dar expressão ao saberfazer tradicional a partir das "falas" de determinados artesãos da cal, nomeadamente daqueles ligados à sua produção. A partir da evidenciação destas "falas", aqui tidas como património imaterial (em conformidade com o que é indicado pela Convenção da UNESCO (ORGANIZAÇÃO..., 2003)), visa-se identificar algumas das particularidades associadas ao processo de construção e aperfeiçoamento do saber/conhecimento tradicional. O que, por outro lado, ao contribuir para uma melhor compreensão deste tipo de conhecimento, pode colaborar para estabelecer pontes entre conhecimento tradicional e conhecimento científico, nomeadamente no que concerne ao campo da salvaguarda do património (MENEZES; VEIGA, 2016).
Refira-se ainda que, a par de aqui privilegiar-se o conhecimento técnico tradicional relacionado com o processo de fabricação da cal, os testemunhos aqui citados e considerados como "falas" não necessariamente foram diretamente recolhidos pelo autor do artigo. Para efeito, recorre-se a estudos realizados com mestres caleiros no âmbito de projetos de investigação desenvolvidos pelo LNEC, em Beja (Alentejo/Portugal). Explora-se ainda alguma literatura nesta área temática, todavia, privilegiando-se os estudos empíricos realizados em Portugal, nomeadamente onde a "voz" do artesão da cal tenha sido expressiva para a compreensão dos processos técnicos tradicionais. As fontes de consulta aqui utilizadas para apresentação e discussão das "falas da cal" são essencialmente: Menezes (2015); Menezes e Veiga (2018); Custódio (2015); Santos (2008a, 2008b, 2012). Os artesãos autores das "falas" citadas são, todavia, devidamente identificados em função da fonte consultada (ver Quadro 2).

\section{Quadro 2 - Identificação dos mestres caleiros citados e fonte consultada}

\begin{tabular}{|c|c|c|c|}
\hline $\begin{array}{l}\text { Nome do } \\
\text { mestre } \\
\text { caleiro }\end{array}$ & Dados de identificação & Local do forno & $\begin{array}{l}\text { Fontes consultadas e } \\
\text { períodos de } \\
\text { realização da } \\
\text { entrevista }\end{array}$ \\
\hline $\begin{array}{l}\text { João } \\
\text { Caetano } \\
\text { Descalço } \\
\text { Galhana }\end{array}$ & $\begin{array}{l}\text { Nascido em 1948, criou-se em Trigaches. Por } \\
\text { volta dos } 30 \text { anos, arrendou com mais um sócio } \\
\text { um forno na zona e começou a produzir cal. } \\
\text { Primeiro alugou o forno e depois comprou, onde } \\
\text { laborou sem interrupção entre } 1976-1981 \text {, } \\
\text { trabalhando no forno entre } 3 \text { - } 4 \text { pessoas. Antes, } \\
\text { trabalhou na pedreira. }\end{array}$ & $\begin{array}{l}\text { Trigaches, Beja } \\
\text { (Alentejo) }\end{array}$ & $\begin{array}{l}\text { Menezes }(2015) \text { e } \\
\text { Menezes e Veiga } \\
(2018) \\
\text { Datas das entrevistas: } \\
01.10 .2014 \text { e } \\
27.05 .2015\end{array}$ \\
\hline $\begin{array}{l}\text { Jacinto } \\
\text { Figueira }\end{array}$ & $\begin{array}{l}\text { Nascido em 1945, começou a trabalhar aos } 8 \text { anos } \\
\text { de idade. A atividade nos fornos iniciou-se por } \\
\text { volta dos seus } 30 \text { anos, mas não era atividade } \\
\text { principal. Foi imigrante em França, onde casou } \\
\text { com uma senhora de Trigaches e teve um filho. } \\
\text { Com os } 5 \text { anos do filho voltaram para Trigaches. } \\
\text { O filho não seguiu a atividade do pai. Foi o } \\
\text { responsável pelo último forno artesanal de } \\
\text { Trigaches e que funcionou até } 2002 \text {. }\end{array}$ & $\begin{array}{l}\text { Trigaches, Beja } \\
\text { (Alentejo) }\end{array}$ & $\begin{array}{l}\text { Menezes }(2015) \text { e } \\
\text { Menezes e Veiga } \\
\text { (2018) } \\
\text { Datas das entrevistas: } \\
01.10 .2014 \text { e } \\
27.05 .2015\end{array}$ \\
\hline $\begin{array}{l}\text { António } \\
\text { Manuel } \\
\text { Festas }\end{array}$ & $\begin{array}{l}\text { Nascido em 1930. O avô e o pai trabalhavam na } \\
\text { laboração da cal, tendo, tomado contato com a } \\
\text { atividade desde criança. }\end{array}$ & $\begin{array}{l}\text { Barro Branco, } \\
\text { Borba (Alentejo) }\end{array}$ & $\begin{array}{l}\text { Custódio (2015) } \\
\text { Data da entrevista: } \\
17.12 .2014\end{array}$ \\
\hline $\begin{array}{l}\text { António } \\
\text { Reis } \\
\text { Brito }\end{array}$ & $\begin{array}{l}\text { Nascido em } 1948 \text { em Santa Rita. O pai já } \\
\text { trabalhava como caleiro. }\end{array}$ & Santa Rita & $\begin{array}{l}\text { Custódio (2015). } \\
\text { Data da entrevista: } \\
28.01 .2015\end{array}$ \\
\hline $\begin{array}{l}\text { José } \\
\text { Palma } \\
\text { Costa }\end{array}$ & Nascido em 1919 e falecido em 2009. & $\begin{array}{l}\text { Caliço, Campismo, } \\
\text { Manta Rota, } \\
\text { Concelho de Vila } \\
\text { Real de St. }^{\circ} \\
\text { António (Algarve) }\end{array}$ & $\begin{array}{l}\text { Santos (2008a, } \\
\text { 2008b, 2012) } \\
\text { Data da entrevista: } \\
\text { entre } 2007 \text { - 2008 }\end{array}$ \\
\hline
\end{tabular}


No desenvolvimento deste artigo, procede-se primeiramente a um breve enquadramento acerca da relação entre conhecimentos tradicional e científico. O objetivo é melhor situar as suas diferenças e semelhanças, deste modo contribuindo para desmitificar determinados preconceitos acerca do que é saber tradicional, bem como estabelecer pontes entre conhecimentos.

No seguimento, são apresentadas determinadas "falas" associados à artesãos que produzem e/ou produziram cal. Neste âmbito e com recurso a uma análise de conteúdo (BARDIN, 1977), identificase um conjunto de especificidades que são particularmente incidentes no processo de elaboração, consolidação e transmissão do conhecimento tradicional (NICHOLAS; MARKEY, 2014; CUNHA, 2007; WHYTE, 2013; DURAN; RIGOLIN, 2011; CHAMOUX, 1981, 2010). O que, essencialmente, permite apresentar e discutir alguns dos contextos sociais, geográficos, materiais e tecnológicos de algumas "falas" relacionadas com quem produz a cal (caleiros). Entretanto, aspectos a reter para não só salvaguardar o conhecimento tradicional enquanto património. Mas também porque importante recurso para o conhecimento científico e a salvaguarda do património numa perspectiva mais ampla (tangível e intangível).

\section{Entre conhecimentos tradicional e científico}

O saber tradicional é, muitas vezes, associado ao uso de técnicas mais simples, o que não corresponde à realidade. No caso dos revestimentos executados com base em argamassas de cal, observa-se uma multiplicidade de técnicas. Por exemplo: as mais sofisticadas (eg.: esgrafito, fingido de pedra ou de tijolo); as mais simples (ex.: barramento, reboco e caiação). Cada um destes revestimentos apresenta peculiaridades no âmbito dos materiais utilizados, das técnicas de aplicação e das soluções estéticas de acabamento, como ainda na forma de interação com o ambiente e a geografia local. A complexidade do saber técnico tradicional manifesta-se ainda na variedade de "artes e ofícios". O que, por outro lado, permite exemplificar o grau de especialização dos artesãos, onde cada se encontra. Isto é, tem-se os mestres construtores, que decidiam sobre a localização e organização da construção e sobre os principais materiais a usar. Tem-se também os mestres pedreiros que tinham competência para executar alvenarias de pedra e construções de pedra em geral; os mestres caleiros que eram os responsáveis pela preparação da cal. Por outro lado, existem ainda os mestres estucadores, que executavam os trabalhos de estuque; os mestres escaioladores, responsáveis pelas decorações com massas pigmentadas fingindo pedra; os rebocadores, responsáveis pelos trabalhos de revestimentos exteriores com funções de impermeabilização (VEIGA, 2010).

Mas, o saber-fazer tradicional não deve ser descrito como se tratando de uma normativa, como se fosse uma receita. Isto porque, é um saber-fazer incorporado. Um saber onde se observam variações nos modos de ação por parte de quem produz/reproduz conhecimento e realiza uma dada ação. O que não só dificulta um registo histórico normativo dos procedimentos técnicos adotados, bem como reduz a riqueza contextual dos significados e processos envolvidos. Isto porque, o processo de produção e reprodução do conhecimento tradicional é diretamente afetado pelas condições sociais e ambientais. Como um corpo de saber aprendido individual ou coletivamente a partir de experiências e explicações, normalmente verificado pelos mestres e os mais velhos e experientes, este conhecimento é, então, preservado e transmitido através das tradições orais (CHAMOUX, 1981, 2010; NICOLAS; MARKEY, 2014). Mas, face aos riscos envolvidos na transmissão oral deste conhecimento, bem como aos riscos que afetam muito do património arquitetónico relacionado com as técnicas e materiais tradicionais (cf. Quadro 1), é consequente e necessário encontrar meios de salvaguarda deste conhecimento. Aqui importa recolher informação relacionada com os processos construtivos tradicionais, o seu registo e sistematização, bem como a sua correta difusão.

Notar, todavia, que o senso comum costuma associar as diferenças entre conhecimentos considerando que o saber tradicional, transmitido ao longo de gerações e utilizado pelos grupos sociais, seria imutável e que, como tal, não introduziria inovação Isto porque é erradamente considerado que o mesmo não envolveria procedimentos lógicos de investigação (MENEZES; VEIGA, 2016).

Estas considerações são, contudo, "mitos". Pois, vejamos, o processo de elaboração de conhecimento tradicional, bem como de conhecimento científico, verifica-se a partir de operações lógicas e racionais. Pelo que, ambos conhecimentos permitem inovar e executar procedimentos investigativos, onde inovação, mudança, processos, práticas e a busca por mais conhecimento com o objetivo de responder a questões concretas, são operações racionais presentes nestes dois tipos de conhecimento. A diferença entre conhecimentos tradicional e científico relaciona-se, essencialmente, com 
princípios: cada um dos tipos de conhecimento em causa interpreta de modo diferenciado o ambiente a sua volta, operando em níveis estratégicos distintos. Assim, por exemplo, é de considerar que o conhecimento tradicional é mais percetivo e ligado às qualidades sensoriais, tais como visão, odor, sabor, tato; enquanto o conhecimento científico opera com unidades conceituais.

No Quadro 3 realiza-se uma sistematização das principais diferenças e semelhanças entre ambos conhecimentos.

As diferenças estratégicas entre conhecimentos científico e tradicional - podem, todavia, ser valoradas ao ter-se presente uma lógica de complementaridade entre ambos. Por exemplo, está-se ciente de que o conhecimento das tecnologias pré-existentes é fundamental para a conservação do património arquitetônico. Isto porque, é um contributo para o definir metodologias de restituição da integridade estética e da capacidade funcional dos edifícios, sem os falsificar nem destruir (VEIGA, 2010).

$\mathrm{O}$ que, por outro lado, permite evidenciar o interesse em promover intervenções que respeitem: a compatibilidade entre materiais novos e antigos, sob pena de causarem outras anomalias; bem como a necessidade de promover uma perspetiva conservativa, o que contribui para evitar a reparação por meio da extração e remoção dos elementos antigos e substituição por elementos modernos. A perspectiva defendida visa sobretudo contribuir para a adoção de soluções reversíveis ou, pelo menos, pouco invasivas e que, para além de proporcionarem uma durabilidade satisfatória, promovam uma integração equilibrada no ambiente envolvente.

Mas, atualmente os edifícios e elementos históricos confrontam-se com situações, por vezes, mais adversas que as iniciais. Isto pode alterar significativamente as condições de manutenção (ex.: mudanças climáticas e ambientais - poluição, vibrações do tráfego automóvel). Por outro lado, isto realça o interesse em investigar mais aprofundadamente as técnicas, materiais e ferramentas tradicionais.

Muito embora realce também o interesse em inovar cientificamente no conhecimento tecnológico, procurando novos produtos para tratamento e proteção face a agressões prolongadas e mesmo novas. Salienta-se ainda que as técnicas físico-químicas de análise permitem conhecer a constituição atual de um elemento construtivo, mas não a sua constituição original: o que se obtém nas análises é o objeto atual, alterado pelos processos decorrentes da ação do tempo, do clima e da ação humana.

Essas técnicas científicas, também, não identificam inteiramente as técnicas de execução, antes permitem avaliar da possibilidade de terem sido usadas determinadas técnicas.

$\mathrm{O}$ conhecimento, à partida dos materiais e técnicas habitualmente usados, permite iniciar um processo iterativo de experimentação, verificação e aperfeiçoamento dos materiais de restauro, designado por alguns autores de "engenharia inversa" (MOROPOULOU et al., 2005).

\section{Quadro 3 - Conhecimentos tradicional e científico: diferenças e similaridades}

\begin{tabular}{|c|c|c|}
\hline Conhecimento científico & Semelhanças & Conhecimento tradicional \\
\hline $\begin{array}{l}\text { Verdade absoluta / Regra da } \\
\text { refutação. } \\
\text { Regra da universalidade. } \\
\text { É hegemónico. } \\
\text { Opera com unidades } \\
\text { conceituais / Usa conceitos } \\
\text { Realiza a análise das partes de } \\
\text { um todo para compreender o } \\
\text { conjunto que as integra. } \\
\text { As partes tendem a ser } \\
\text { separadas em biofísica, } \\
\text { mundo humano e } \\
\text { sobrenatural. } \\
\text { É codificado, categorizado, } \\
\text { apreendido e reproduzido } \\
\text { formalmente. }\end{array}$ & $\begin{array}{l}\text { Relacionam-se com os seus } \\
\text { praticantes } \\
\text { Resultam de um conjunto de } \\
\text { práticas } \\
\text { Respeitam a processos e } \\
\text { adotam modos específicos de } \\
\text { fazer e investigar, não } \\
\text { estando dependentes de } \\
\text { acervos estáticos } \\
\text { Assentam em operações } \\
\text { lógicas comuns em busca de } \\
\text { saber mais } \\
\text { Recorrem a repetição, } \\
\text { inferência, predição e as } \\
\text { observações empíricas } \\
\text { Identificam padrões modelo } \\
\text { Estão sujeitos a improvisação }\end{array}$ & $\begin{array}{l}\text { A universalidade não se aplica. É mais } \\
\text { tolerante, considera explicações } \\
\text { divergentes, ainda que a validade seja } \\
\text { particular e associada a um contexto } \\
\text { específico. } \\
\text { Opera com unidades perceptuais / Usa } \\
\text { perceções. } \\
\text { Opera com qualidades segundas: cheiros, } \\
\text { cores, sabores (etc.). } \\
\text { Integra a parte e o todo, não havendo } \\
\text { separação. } \\
\text { Realiza-se a partir de vínculos de } \\
\text { continuidade entre os âmbitos biofísico, } \\
\text { humano e sobrenatural. } \\
\text { Enquadra-se contextualmente e articula } \\
\text { espaço/tempo, geografia/cultura local. } \\
\text { É tácito e apreendido através da } \\
\text { vivência. }\end{array}$ \\
\hline
\end{tabular}

Fonte: Menezes e Veiga (2016). 
Mas, as tentativas de validação científica do conhecimento tradicional não são vantajosas para estabelecer-se a complementaridade entre conhecimentos. Por outro lado, não se trata de aceitar-se de forma irrestrita e sem questionamento o que o conhecimento tradicional refere. A complementaridade pode, por exemplo, realizar-se através do recurso a este saber técnico com vista a melhor compreender determinados materiais, processos ou mesmo categorias ainda não decifradas pelo saber científico. Observando-se ainda que o registo e devida difusão deste conhecimento é um importante contributo para valorizar o património imaterial, contribuído para a sua salvaguarda.

Portanto, no campo da conservação do património e tendo presente a premente questão da criação de condições de sustentabilidade dos recursos patrimoniais, poderá ainda interessar aprender com o conhecimento tradicional no sentido da proposição de novas hipóteses de atuação. De um ponto de vista científico interessará, por exemplo, interpretar as expressões usadas, perceber quais as razões explicativas de determinadas expressões adotadas pelo saber-fazer artesanal.

\section{Falas sobre o fazer tradicional da cal}

No caso da estruturas e processos produtivos de cal tradicional (ou artesanal), sabe-se que a par da existência de vestígios de locais onde funcionaram fornos de cal, carece a realização de estudos sistemáticos sobre estas estruturas produtivas tradicionais (MARGALHA et al., 2008). Neste sentido, ao falar dos materiais de construção vernacular em Portugal, Pedro Prista (2014) observa a pouca atenção que se tem dedicado a tais estruturas produtivas, referindo que são:

\section{[...] obras exigentes na sua construção, e plasticamente interessantes, parecem surpreendentemente reduzidos os registos a que os fornos da cal deram origem, sobretudo se compararmos com outras construções não habitacionais, como poços, fontes, fornos domésticos e coletivos, soengas ou até abrigos de pedra. (PRISTA, 2014, p. 115).}

Mas, ainda que tardiamente, pouco a pouco, observa-se o aumento do interesse pelo conhecimento destas estruturas produtivas, bem como pelos processos tecnológicos envolvidos.

À semelhança do que se verificou com o interesse científico pelos revestimentos históricos sobretudo a partir de finais dos anos de 1970, muito embora a defesa pela conservação dos mesmos se enfatize somente a partir de finais dos anos de 1980 (TAVARES, 2011), na sequência do estado da arte sobre a temática dos fornos de cal conforme efetuada por Paulo Custódio (2015), nota-se que é a partir da última década do século $\mathrm{XX}$ que se verifica um progressivo aumento de interesse académico e científico pelo assunto.

É, portanto, na sequência do interesse em contribuir para aumentar o conhecimento sobre os processos e técnicas de produção da cal artesanal que seguidamente privilegia-se apresentar de modo sistematizado algumas "falas" de quem faz/fez a cal em contexto português. Para efeito, considerase os seguintes aspectos: a designação do ofício tradicional; contexto social e ambiental de realização do ofício; descrição das etapas técnicas, ferramentas e materiais envolvidos no desenvolvimento do ofício; descrição dos modos de aprendizagem, difusão e riscos de transmissão do ofício.

\section{Sobre a atividade de caleiro: o fazedor de cal}

O trabalhador no forno de cal é designado como caleiro:

O caleiro é quem trabalha no forno de cal. Monta as pedras e trata das lenhas, faz tudo. Antigamente diz que havia uns homens mais entendidos na pedra cozida. As pedras depois de estarem cozidas, tem que se conhecer se está cozido o forno ou se não está. Perceber que já estão no ponto de cozedura. Antigamente haviam uns homens, que não trabalhavam, só viam, estava o forno quase no fim, vinham ver quando estava cozido [...]. (Sr. José Palma Costa (SANTOS, 2012).

O caleiro é, assim, quem escolhe e traz a lenha; escolhe, separa as pedras (em termos das mais adequadas para a montagem do forno e o cozimento, em termos da produção de cal branca e cal preta ou parda, e as seleciona para a montagem do forno (em termos das pedras que irão compor a estrutura do forno (fundamental para a estabilidade do forno) (SANTOS, 2008a, 2008b); sendo também quem faz o desmonte do forno. Na verdade, a melhor definição do que faz um caleiro é a do mestre Jacinto, e que também é a citação que intitula este artigo, nomeadamente quando refere que aa atividade do caleiro é "fazer, cozer, tirar a cal". 


\section{Um saber-fazer assente numa geografia de proximidades}

Segundo Margalha et al. (2008), os fornos tradicionais de cal costumam, em Portugal, localizarem-se próximos da matéria-prima necessária para a produção da cal, isto é, áreas com calcário ou pedra mármore e, por este motivo, estão muitas vezes próximos de pedreiras (ver Figuras 2 a 5).
No sul do País, por exemplo, observa-se a concentração de fornos artesanais próximo de afloramentos de rochas carbonatadas, de que são exemplos os mármores de Estremoz, os calcários do barrocal algarvio e os mármores de Trigaches, onde "por um lado os caleiros aproveitavam as pedras pequenas já arrancadas do solo, por outro, os encarregados das pedreiras livravam-se dos restos sem valor comercial" (cf. mestres caleiros Sr. António M. Festas e Sr. Jacinto Figueira (CUSTÓDIO, 2015).

Figura 2 - Aldeia de Trigaches, Distrito de Beja

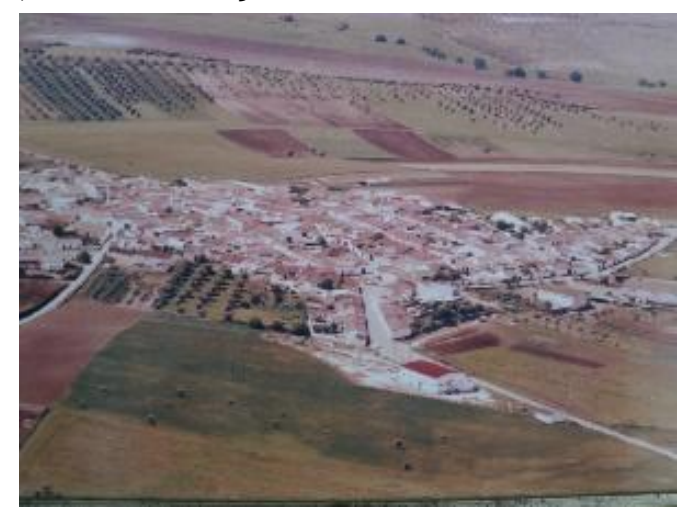

Figura 3 - Pedreira de Trigaches, Distrito de Beja de onde eram retiradas as pedras para os fornos de produção de cal artesanal - pedreira atualmente desativada

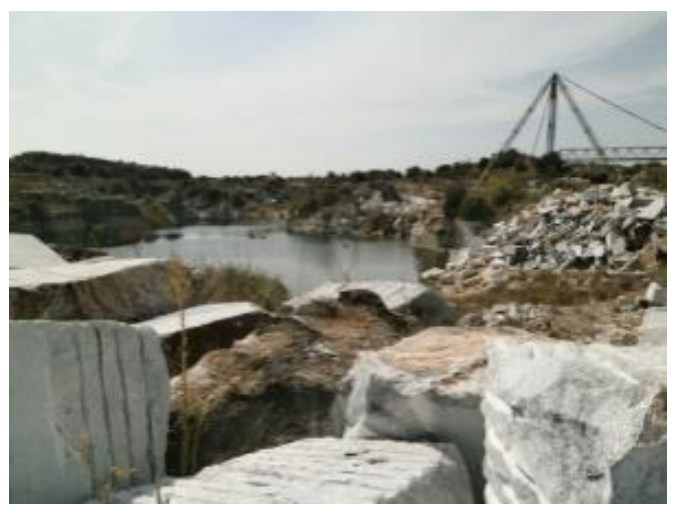

Figura 4 - Forno tradicional de Trigaches, em Beja, próximo da pedreira e de materiais combustíveis para a lenha utilizada - forno desativado

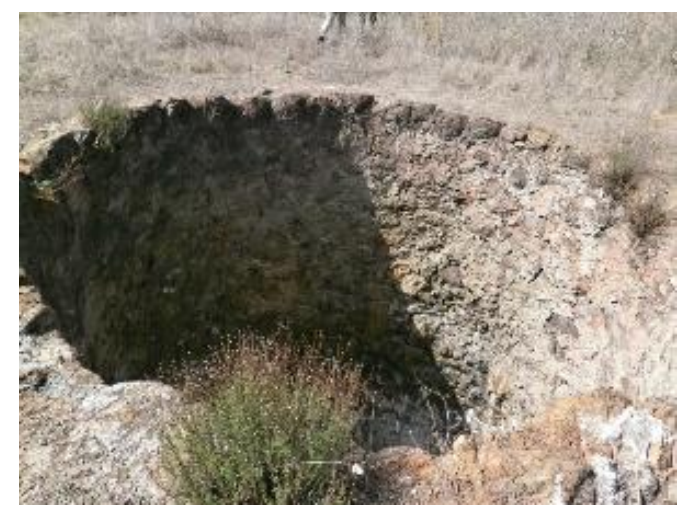

14 Menezes, $M$. 
Figura 5 - Forno tradicional desativado (Trigaches, Beja)

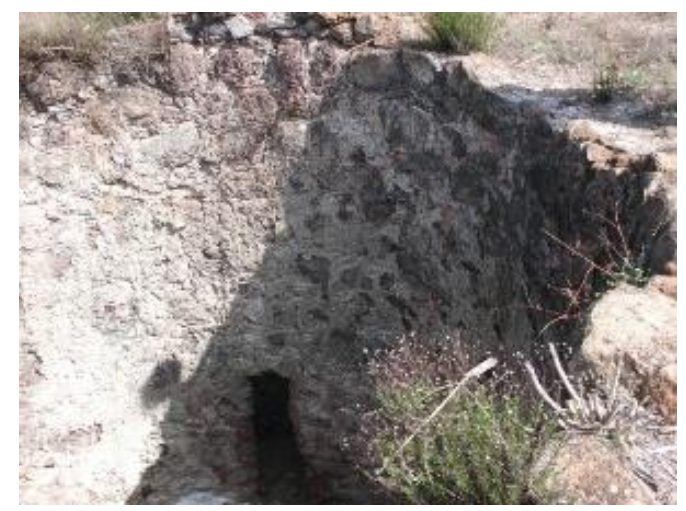

Todavia, o sítio de localização destas estruturas possa também aparecer em lugares não necessariamente próximos dos afloramentos rochosos calcários, como é o caso dos fornos do baixo Guadiana, localizados ao longo da margem do rio (CUSTÓDIO, 2015). Mas com acesso facilitado à lenha para a combustão.

Também fazíamos estes fornos onde é que estava a lenha mais próxima, nem sempre se fazia o forno mesmo ao pé do lugar da pedra de cal. Também não faziam perto da aldeia. Nós íamos buscar as pedras nas pedreiras e as pessoas depois iam lá buscar a cal, em carros carregados. [...]O forno era um buraco. O forno era feito ao pé da lenha porque a lenha dava mais trabalho a acatar. Dava mais trabalho que a pedra. A pedra vinha em carros, haviam tabins por onde os carros passavam, e a lenha apanhava-se no mato, à volta, trazida às costas [...]. (Sr. José Palma Costa).

Os fornos tradicionais costumam ser explorações familiares, com situações em que a sua exploração é feita por uma mesma família durante várias gerações. Noutras vezes, os fornos eram arrendados. A família e, em alguns outros casos, os mestres locais, são os principais elos de transmissão do conhecimento tradicional.

O meu pai não fazia, mas vendia a cal em carroça [...]. Eu desde pequenino estava ligado, ia lá ajudar a descarregar ..., os meus avós estavam ligados aos fornos. (mestre Jacinto Figueira).

[...]Oh pá, o meu pai cozia, foi desde pequeno ... foi sempre a minha vida, a minha vida foi essa. I (A gente só fazia aquilo ... o meu pai só fazia aquilo. (mestre António Reis Brito).

Esteve aqui o meu avô [...] ele morreu com 89 anos, se eu não estou em erro, depois esteve o meи pai, que morreu com 92.
Naquela altura já se cozia aqui a cal ... e por aqui tinham passado também outros. $O$ forno já [...] estava abandonado, e depois a gente é que o foi amanhando aí [...]. (Sr. António M. Festas).

[...] No princípio, quando era moço, ainda não tinha conhecimento, não sabia fazer o serviço. Havia dois homens que coziam e havia um a juntar, a acartar a lenha para o pé do forno, para eles queimarem. E houve vezes, era eu moço e levava um preço para andar lá a ajudar, e eu ia porque ganhavam os dias, a noite contava como um dia. Aprendi com essas pessoas. Vi como elas faziam e depois fui aprendendo. Não foi o meu pai que me ensinou. O meu pai era bagoão. Fazia carros, fazia arados, fazia carroças, antigamente. Trabalhava com madeira. Eu nunca cheguei a fazer isso. (Sr. José Palma Costa).

Um conhecimento realizado a partir de vínculos de proximidade dos materiais, da geografia e sociedade local. Um saber-fazer tácito e aprendido através da vivência. O que é consistente com o comentário que Paulo Custódio faz ao referir o mestre caleiro António Reis e que, remetendo para a "origem da cal", faz também pensar numa espécie de mito de origem da cal, já que,

[...] os homens descobriram a cal quando, ao fazerem uma fogueira cercada de pedras calcárias, se aperceberam que a rocha original, quando exposta às elevadas temperaturas do fogo, se transformava noutro material [...]; (CUSTÓDIO, 2015, p. 5).

Um conhecimento técnico que é, entretanto, muito pessoal: cada "fala" sobre o saber-fazer é única, reflete experiências pessoais, segredos próprios sobre o saber-fazer. Enfim, tudo "[...] coisa que se iam aprendendo [...]" (Sr. Jacinto Figueira); coisas que "[...] conhece-se [...] eu conheço, há pessoas 
que não conhecem [...] é a experiência [...]" (Sr. António Reis Brito).

Como observado por Custódio (2015, p. 55), ainda que os mestres não detivessem um conhecimento acerca das composições mineralógicas das pedras apropriadas para a cal branca e a cal preta, "sabiam que a pedra de cal preta calcinava mais depressa que a pedra de cal branca, e engenhosamente, tiraram partido dessa diferença para calcinar cal preta e cal branca em simultâneo, embora em diferentes proporções". Esta experiência técnica adquirida de modo tácito e vivido é ainda e, por exemplo, evidenciada em duas das questões que Custódio (2015) faz ao mestre caleiro, Sr. António Reis Brito, nomeadamente:

Custódio: Qual é, aproximadamente, o diâmetro do poço do forno?

Mestre: Isso não sei ... nem vale à pena pensar [...].

Custódio: Existe alguma relação entre o diâmetro e a profundidade do poço do forno?

Mestre: Exatamente, tem de ser uma coisa combinada uma com a outra. Tem de ser a fundura com a altura, mais ou menos o mesmo (...), mas isso tens de medir. Tem de ser aquela altura com aquela largura.

Em síntese, na busca pelo saber, o conhecimento académico e científico, representado pelas questões antes colocadas, opera com unidades conceituais e realiza a análise de um todo a partir das suas partes. Já o conhecimento tradicional, representado pelas respostas do mestre, opera com percepções e qualidades segundas (cheiros, cores, sabores, impressões visuais etc.), combina a parte e o todo, é tácito e realiza-se sobretudo a partir de uma experiência que articula a geografia e a cultura local (MENEZES; VEIGA, 2016).

\section{Sobre os processos e modos de laboração}

Os fornos de cal costumam ser estruturas semienterradas e cilíndricas, em alvenaria de pedra resistente ao calor. Ao meio é colocada a pedra que, após o cozimento, fornece a cal branca e a cal preta ou parda. A aplicação da cal na construção é muito diversificada, indo desde a sua aplicação como "[...] ligante de argamassas de assentamento e revestimento de alvenarias, sobretudo no restauro de edifícios antigos [...]” à “[...] estabilização do adobe e da taipa; no esgrafito e nos trabalhos de massa; na caiação ou na escaiola/estuque de alvenarias [...]", entre outros aspectos (CUSTÓDIO, 2015, p. 52).
[...] [o forno] é alvenaria de pedra com barro, mas a pedra é diferente, é da zona de Beringel, é dessa pedra escura com que fazem os paralelos da calçada [...] não é mármore, se fosse feito de mármore desfazia-se, cozia e se desfazia [...] Há uma britadeira ao pé de Ferreira, quando se vai de Beringel para Ferreira, que também utiliza essa pedra escura [...]. (Sr. Jacinto Figueira).

Tendo em conta que os dois processos de produção da cal dão lugar a duas distintas tipologias de fornos - laboração intermitente e com o lume na base; laboração contínua ou forno de empilhamento (CUSTÓDIO, 2015), os mestres caleiros aqui citados sobretudo trabalharam em fornos de laboração intermitente. Santos (2012, p. 103) ao referir-se aos fornos tradicionais da Região do Algarve observou que,

[...] os caleiros locais referenciam o forno de cal intermitente como o mais corrente, caracterizado pela produção cíclica de cal num processo repetido de enfornagem, cozedura e desenformagem do forno [...].

Um processo descrito pelo mestre Jacinto Figueira como sendo "formar, cozer, tirar a cal". Com o início do processo de laboração é importante garantir que o forno funcione de forma contínua, num processo lento e compassado: a pedra calcária transforma-se em cal viva a partir de um processo de transformação que é assegurado pela manutenção de uma temperatura constante entre os $800{ }^{\circ} \mathrm{C}$ e os $1000{ }^{\circ} \mathrm{C}$.

$O$ forno tem de funcionar continuamente, senão arrefece, daí tinham que estar aqui durante o período de cozimento. [...] Se não houvesse vinho para dar a disposição, não vinham fazer [...] Faziam turnos, dormiam debaixo de qualquer árvore e depois vinham fazer [...]. (Sr. Jacinto Figueira).

O forno de é redondo com abóboda, o da telha é quadrado. Tem tudo a ver com a forma com que o fogo trabalha melhor. Tem de se buscar a melhor forma, que dê melhor resultado. $O$ fogo do forno de cal tem de trabalhar ao meio, porque o forno para a pedra de cal é em redondo e, assim, o calor dali do meio cozia a pedra à roda e não queimava. $O$ forno para pedra leva mais tempo a cozer, é um outro fogo. É um fogo compassado, lentamente, que a pedra precisa de menos calor que a terra $e$ precisa de ir cozendo lentamente, sempre com o mesmo fogo [...] Coisas da Natureza. [...] A cozedura durava horas, era conforme o tamanho do forno. Leva ali 
gente a trabalhar dias seguidos, para as pedras cozerem todas. E tem que ser um fogo especial! Tem que ser rijo, tem que ser um fogo que não pode parar. Tem que ser um fogo que vai sempre aumentando, cozendo, só com o calor do fogo. (Sr. José Palma Costa).

\section{Uma tradição em desaparecimento?}

Para a produção artesanal de cal é necessário muito esforço físico, estando a propriedade dos fornos normalmente associada à uma pessoa idosa, entretanto nem sempre apoiada pelos mais novos.

[...] Acho bem os filhos não terem seguido o ofício. Trabalhando como eu trabalhava, por minha conta, tinha que ser uma coisa pegada, não tinha férias, não tinha dias feriados, não tinha nada [...], muito suor, $e$ com o suor, às vezes, fazia-se regar a cal" / "... antes trabalhar nos fornos, trabalhava nas pedreiras, quem trabalhava tinha mais, mas o que dava era para a sopa. (Sr. João Galhana).

Comecei a trabalhar já na barriga da minha mãe. [...] Para além do forno da cal, trabalhava no que aparecia, trabalhava-se na pedreira [...]. [...] dormia-se com um pé no forno. [...] As pessoas deixaram de usar a cal porque deixou de haver, mas é um trabalho duro: pegar lenha, partir a pedra [...]. (Sr. Jacinto Figueira).

Era um trabalho muito duro, mãe! Estoulhe a contar, mas só quem passou é que sabe [...]. [...]ficávamos com feridas nas mãos, muitas e finas, depois de muito mexer nas pedras para as pôr bem [...]. Com as feridas íamos mexer na cal. Era um trabalho muito ingrato. (Sr. José Palma Costa).

Aspectos que, associados à concorrência dos produtos industriais, contribuíram para o desaparecimento gradual, em território nacional, da cal feita em forno tradicional (MARGALHA et al., 2008).

Antigamente as pessoas aqui em Trigaches trabalhavam todas na cal, a partir a pedra, outras na lenha, outras a vender, outros nos fornos [...]. [...] é a moda, mais moderno agora, é as tintas e pronto. (Sr. João Galhana - ver Figura 6)

Havia muitos fornos, fornos haviam muitos. Naquela altura vivia-se nesta aldeia só através dos fornos de cal. [...] Foi a atividade principal da aldeia ... e de outras aldeias aqui próximas. Ali na Nora, uma aldeia aqui próxima, também havia ali fornos. [...]Era só começar a cozer $e$ apareciam logo aí mulheres, que viam o fumo do forno, para comprar a cal para caiar. (Sr. António Manuel Festas).

As pessoas fazem as casas de maneira sempre igual. As pessoas passaram a fazer as casas em blocos de cimento. Antes faziam os blocos com cal, faziam-se muitos blocos assim deste tamanho, em cal, levava brita, levava casca de berbigão, casca de marisco. E fazia-se com uma forma. Os adobes eram para fazer casas. E depois passaram a fazer de cimento [...]. (Sr. José Palma Costa).

[sobre voltar a usar-se cal artesanal] [...]procura não sei se haverá porque as pessoas já se habituaram à tinta. $O$ pedreiro já se sabe, gastam dessa industrial, e as velhotas que caiavam as casas vão desaparecendo [...]. Quando deixou de trabalhar, a maioria dos fornos já tinha fechado, e aqueles de Santarém também [...], havia fornos por todo o lado, mas agora já não há. Os fornos lá agora (em Santarém) são com aquelas britas mais pequenas e os fornos são eléctricos. ( $\mathrm{Sr}$. Jacinto Figueira - ver Figura 7). 
Figura 6 - Senhor João Caetano Descalço Galhana, caleiro de Trigaches a explicar no local do forno desativado o processo de produção da cal

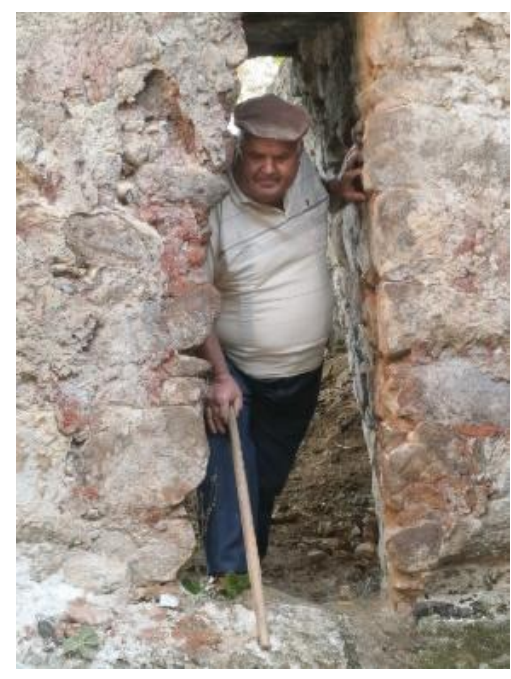

Figura 7 - Senhor Jacinto Figueira, caleiro de Trigaches a explicar no local do forno desativado o processo de produção da cal

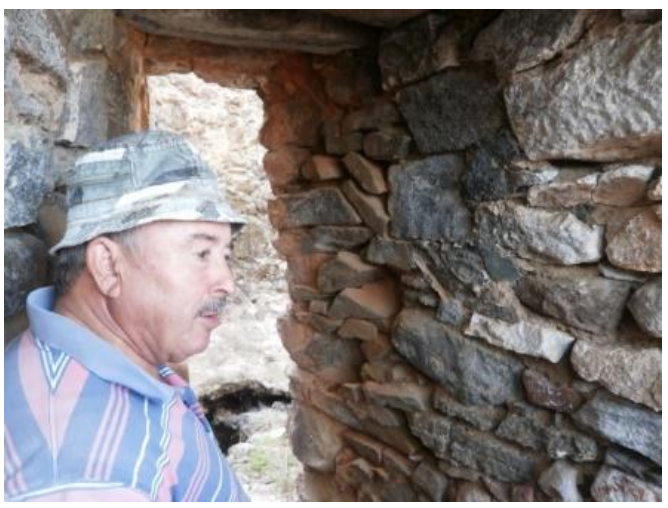

No entanto, a par da concorrência feita à cal pelos produtos industriais, os mestres caleiros consideram que:

A cal é melhor que a tinta. Se caiar com a cal hoje cedo, à noite já se pode lá dormir, não tem aquele cheiro. [...]A cal é mais fresquinha. [...] $O$ reboco feito com a cal é mais prático, seca mais rápido, e misturase com cimento, é mais prático. [...]O reboco não se torna tão húmido, e um reboco feito com cimento estala por todo o lado"; "... e quando não faziam com cimento era só com a cal [...]. (Sr. Jacinto Figueira).

Se você pintar o seu quarto com tinta, à noite pode lá dormir? Se for caiado com cal, pode. E sente-se bem porque a cal é saudável. (Sr. João Galhana).

Se eles me comprassem a cal, eu cozia, agora cozer para deitar fora não vale à pena. Eu já estou velho, mas ainda fazia isso e fazia mais depressa para as mulheres aí dos moços virem a ver [professoras com turmas de alunos], não sabem nada [...] eu digo, mas eles não sabem. [...] Era branca. Antes era preta. Quando deixaram de utilizar para as obras, passou a ser branca só. Era branca para a escaiola e para caiar, mais nada [...], a preta acabou. Ainda hoje há mercado para a branca, o que é, é que a gente não coze [...], vem lá de cima de Alcanede. (Sr. António Reis Brito).

\section{A tradição transforma-se: notas finais}

Como antecipadamente referido, o presente trabalho visou retratar "falas" que, ao indiciar processos tecnológicos de "formar, cozer, tirar a cal" (Sr. Jacinto Figueira), permitem detectar aspectos comuns entre determinados métodos tradicionais de trabalho e de uso de materiais. Mas, 
permitem detetar também diferenças que tanto se reportam as geografias de enquadramento da experiência dos artesãos, bem como às suas próprias individualidades. O que faz com que, por exemplo, observem-se muitas situações em que um mesmo tema é descrito através de um "falar" muito particular.

No entanto, esta reflexão não abordou todas os assuntos "falados" pelos artesãos aqui referenciados, nem explorou as potencialidades de uma análise de conteúdo mais detalhada e pormenorizada.

$\mathrm{Na}$ verdade, o presente trabalho constitui apenas um dos passos de um processo de investigação que se pretende mais amplo em termos da recolha oral do saber-fazer associado às atividades da cal. Um trabalho que ainda se propõe de organização e sistematização desta informação numa base de dados sobre materiais históricos. Um trabalho que se realiza em prol da discussão sobre os potenciais contributos de uma maior articulação entre conhecimento científico e tradicional no campo da conservação do património. Olhando ainda o interesse de um maior investimento nas articulações interdisciplinares para melhor explorar e aprofundar os significados técnicos e materiais expressos nos registos etnográficos do sabertradicional, entre outros aspectos.

Não menos importante será considerar a importância de se continuar a investir em estudos conforme desenvolvidos por jovens investigadores, como é o caso de Custódio (2015) e Santos (2008a, 2008b, 2012).

Os aspectos da tecnologia tradicional aqui referidos e mesmo os modos e formas como são transformados em discurso e, por consequência, em fonte oral, são um património de conhecimento essencial para o campo da conservação. Isto é, provavelmente um sentido e mesmo significado mais antigo dos usos da cal tradicional e artesanal já não existam ou estão em desaparecimento e, como tal, a sua produção tenha diminuído, assim, contribuindo para a desativação de muitos dos fornos até então existentes. Todavia, a tradição não deve ser compreendida como algo do passado que, como tal, é estático. Isto porque a tradição é dinâmica, se transforma, introduz novos elementos e atualiza-se constantemente, assim como se verifica com o saber-fazer tradicional. O que, tendo em consideração que no campo do património são muitas as possibilidades de uso e aplicação da cal tradicional e artesanal na conservação e restauro do património arquitetónico, muito se faz por explorar. Mas é também no campo da conservação do património que emerge o interesse em salvaguardar o saber- fazer tradicional relacionado com as artes da cal como património imaterial.

\section{Referências}

ALBERTI, V. Manual de História Oral. Rio de Janeiro: FG, 2004.

BARDIN, L. Análise de Conteúdo. Lisboa: Edições 70, 1977.

BENJAMIN, W. O Narrador: considerações sobre a Obra de Nikolai Leskov. In: MAGIA e Técnica, Arte e Política. São Paulo: Ed. Brasiliense, 1986.

BOSI, E. Memória \& Sociedade: lembrança de velhos. São Paulo: Companhia de Letras, 1979.

CHAMOUX M. N. La Transmission des SavoirFaire: un objet pour l'ethnologie des techiniques? Techniques \& Culture, v. 1, n. 54/55, p. 139-161, 2010.

CHAMOUX, M. N. Les Savoir-Faire Techniques et Leur Appropriation: le cas des Nahuas du Mexique'. L'Homme, v. 21, n.3, p. 71-94, 1981.

CUNHA, M.C. Relações e Dissensões Entre Saberes Tradicionais e Saber Científico. Revista USP, v. 75, p. 76-84, 2007.

CUSTÓDIO, P. Os Fornos de Cal do Baixo

Guadiana: contributo para um estudo arquitectónico. Évora, 2015. Tese (Mestrado em Arquitetura) - Escola de Artes, Universidade de Évora, Évora, 2015.

DURAN, M. R. C.; RIGOLIN, C. C. D. Os Múltiplos Sentidos do Conhecimento Tradicional: um conceito em construção.Revista Brasileira de Ciência, Tecnologia e Sociedade, v. 2, p. 73-85, 2011.

MARGALHA, M. G. et al.Traditional Lime Kilns: industry or archaeology? In: HISTORICAL MORTARS CONFERENCE, Lisboa, 2008. Proceedings... Lisboa: LNEC, 2008.

MENEZES, M. Histórias da Cal: o que contam os caleiros acerca da produção da cal artesanal. Lisboa: LNEC, 2015.

MENEZES, M.; TAVARES, M. L.; VEIGA, M. R. Os Revestimentos Exteriores dos Edifícios Históricos Como Parte da Imagem da Cidade: desafios socio-ambientais à sua conservação. In: ROMERO, M. et al. (Orgs.). Reabilitar o Urbano. Brasília: Faculdade de Arquitetura e Urbanismo da Universidade de Brasília, 2012.

MENEZES, M.; VEIGA, M. R. Entre Tradição e Inovação Tecnológica: desafios à conservação do Património em cal. Conservar Património, v. 24, p. 45-74, 2016. 
MENEZES, M.; VEIGA, M. R. Técnicas Tradicionais de Revestimentos: relato de entrevistas com artífices caleiros sobre a produção de cal.Lisboa: LNEC, 2016.

MOROPOULOU, A. et al. Reverse Engineering: a proper methodology for compatible restoration mortars. In: WORKSHOP REPAIR MORTARS FOR HISTORIC MASONRY, Delft, 2005.Proceedigns... Delft, 2005.

NICHOLAS, G.; MARKEY, N. M. Traditional Knowledge, Archaeological Evidence, and Other Ways of Knowing. In: CHAPMAN, R.; WYLIE, A. (Eds.), Material Culture as Evidence: Best Practices and Exemplary Cases in Archaeology. London: Routledge Press, 2014.

ORGANIZAÇÃO DAS NAÇÕES UNIDAS PARA A EDUCAÇÃO, A CIÊNCIA E A CULTURA. Convenção Para a Salvaguarda do Património Cultural Imaterial. 2003.

PRISTA, P. Terra, Palha e Cal: ensaios de antropologia de construção vernacular em portugal. Lisboa: Argumentum, 2014.

SANTOS, M. Argamassas e Revestimentos. In: MATERIAIS, sistemas e técnicas de construção tradicional: contributo para o estudo da arquitectura vernácula da região oriental da serra do Caldeirão. Porto: Edições Afrontamento, 2008.

SANTOS, M. As Superfícies Arquitectónicas da Região do Algarve: contributos para a salvaguarda dos revestimentos tradicionais. Lisboa, 2012. Tese (Mestrado em Arquitetura) Faculdade de Arquitectura, Lisboa, 2012.

SANTOS, M. Fornos de Cal. In: MATERIAIS, sistemas e técnicas de construção tradicional: contributo para o estudo da arquitectura vernácula da região oriental da Serra do Caldeirão. Porto: Edições Afrontamento, 2008b.
SANTOS, M. Fornos de Cal. In: MATERIAIS, sistemas e técnicas de construção tradicional: contributo para o estudo da arquitectura vernácula da região oriental da Serra do Caldeirão. Porto: Edições Afrontamento, 2008a.

TAVARES, M. L. A Conservação e o Restauro de Revestimentos Por Pinturas Exteriores de Edifícios Antigos: uma metodologia de estudo e reparação. Lisboa: LNEC, 2011.Teses e Programas de Investigação, TPI 67.

VEIGA, M. R. O Relacionamento das Estruturas de Base Científica Com os Artistas dos Ofícios Tradicionais. In: AS IDADES da construção. Técnicas e saberes da construção tradicional e sua aplicação à arquitectura contemporânea. Lisboa: IEFP, 2010.

WHYTE, K. P. On the Role of Traditional EcologicalKnowledge as a Collaborative Concept: a philosophicalstudy. Ecological Processes,v. 2, n. 7, 2013.

\section{Agradecimentos}

Esta reflexão deriva de interesses inscritos nos projetos PRESERVe (2014-2017) - Preservação de revestimentos do património construído com valor cultural: identificação de riscos, contributo do saber tradicional e novos materiais para conservação e proteção (LNEC); Dur-Heritage (2014-2017) - Durabilidade e caraterização de materiais com interesse histórico; DB-HERITAGE (2016-2019) - Base de dados de materiais de construção com interesse histórico e patrimonial (FCT - PTDC / EPH-PAT / 4684/2014 - http://dbheritage.lnec.pt/).

\section{Marluci Menezes}

Departamento de Materiais | Laboratorio Nacional de Engenharia Civil | Av. do Brasil, 101, Alvalade | Lisboa - Portugal | 1700 | Caixa Postal 1700066 | Tel.: (351) 21 844-3587 | E-mail: marluci@lnec.pt

\section{Revista Ambiente Construído}

Associação Nacional de Tecnologia do Ambiente Construído

Av. Osvaldo Aranha, $99-3^{\circ}$ andar, Centro

Porto Alegre - RS - Brasil CEP $90035-190$

Telefone: +55 (51) 3308-4084

Fax: +55 (51) 3308-4054

www.seer.ufrgs.br/ambienteconstruido

E-mail: ambienteconstruido@ufrgs.br 